\title{
ASYMPTOMATIC ANEURYSMAL PORTOSYSTEMIC VENOUS SHUNT: A CASE REPORT AND REVIEW OF THE LITERATURE
}

\author{
Levent Filik' ${ }^{1}$, Sedat Boyacioglu \\ Ankara Teaching and Research Hospital, Turkey: Department of Gastroenterologyli ${ }^{1}$ Mesa Hospital, Ankara, Turkey: \\ Department of Gastroenterology ${ }^{2}$
}

Summary: Spontaneous intrahepatic portosystemic venous shunt (SIPSVS) is relatively rare and not well recognized. Herein, we report 75-year-old female of an aneurysmal portosystemic venous shunt detected by colour Doppler ultrasound in check-up examination. A direct vascular communication between left portal vein and middle hepatic vein was confirmed by CT-angiography. The cause of intrahepatic portosystemic venous shunt is disputed. This abnormality, mainly described in cirrhotic liver and rarely in healthy liver, is usually revealed by hepatic encephalopathy or glycoregulation disorders. However, with improvements in imaging the number of reports of SIPSVS identified incidentally in patients without definite symptoms increasing.

Key words: Intrahepatic portosystemic shunt; CT-angiography; Aneurysm

\section{Introduction}

Macroscopic intrahepatic portosystemic venous shunts is defined as communications between the portal and the systemic venous circulation, measuring more than $1 \mathrm{~mm}$ in diameter, and at least partially located inside the liver. Portosystemic shunts are expected to be associated with portal hypertension, trauma, surgical intervention or liver biopsy, but incidentally seen otherwise normal individuals. These spontaneous intrahepatic portosytemic shunts (SIPSVS), except for dilated paraumbilical veins caused by portal hypertension, have generally been considered to be rare even though modern imaging modalities have successfully demonstrated these abnormalities $(5,10,12,14,18,19,21$, 23,27,28). We describe a case with a SIPSVS incidentally diagnosed in check-up investigations.

\section{Case Report}

A 74-year-old female admitted to clinic for health screening. She had no history of trauma, liver biopsy and surgical operation. There had been no episode of hepatic encephalopathy or hypoglycemic symptom. Laboratory data showed normal blood counts, liver and renal function tests, glucose and lipid levels. Ultrasonography, an examination for screening, delineated a snail-like anechoic area in the liver, its connection with the portal and hepatic veins, and marked dilatation of the veins connecting with the shunt in an area with $7 \mathrm{~cm}$ diameter in the left lobe of the liver. Parenchymal echogenicity of the rest of the liver was normal and there was no focal parenchymal lesion. The main portal vein was patent and the course of the right and left portal veins was normal. Colour Doppler imaging showed turbulent flow in the portosystemic venous shunt. CT-angiography demonstrated an aneurysmatic SIPSVS of $23 \mathrm{~mm}$ diameter, between the left hepatic vein and the left portal vein in left lobe. Adjacent to that lesion, a couple of small (3-5 mm) SIPSVS were also seen (Figure 1). She was informed and reassured about that vascular abnormality. But, no intervention was performed because she did not have any symptom or finding.

One year later, the sonographic examination was repeated and no difference was found from the previous one. Then, she was undertaken follow-up.

\section{Discussion}

Although recent advances in USG and CT have detected asymptomatic SIPSVS in an increasing number of patients, SIPSVSs are rarely seen disorder. Park et al. categorized them into four different morphologic types (27). The most common type is a single large tube of constant diameter that connects the right portal vein to inferior vena cava. Type I includes patent paraumbilical veins, located in the liver. Shunts of this type are considered to be collateral pathways which develop in the hepatic parenchyma as a result of portal hypertension. The second type is localised peripheral shunt in which single or multiple communications 

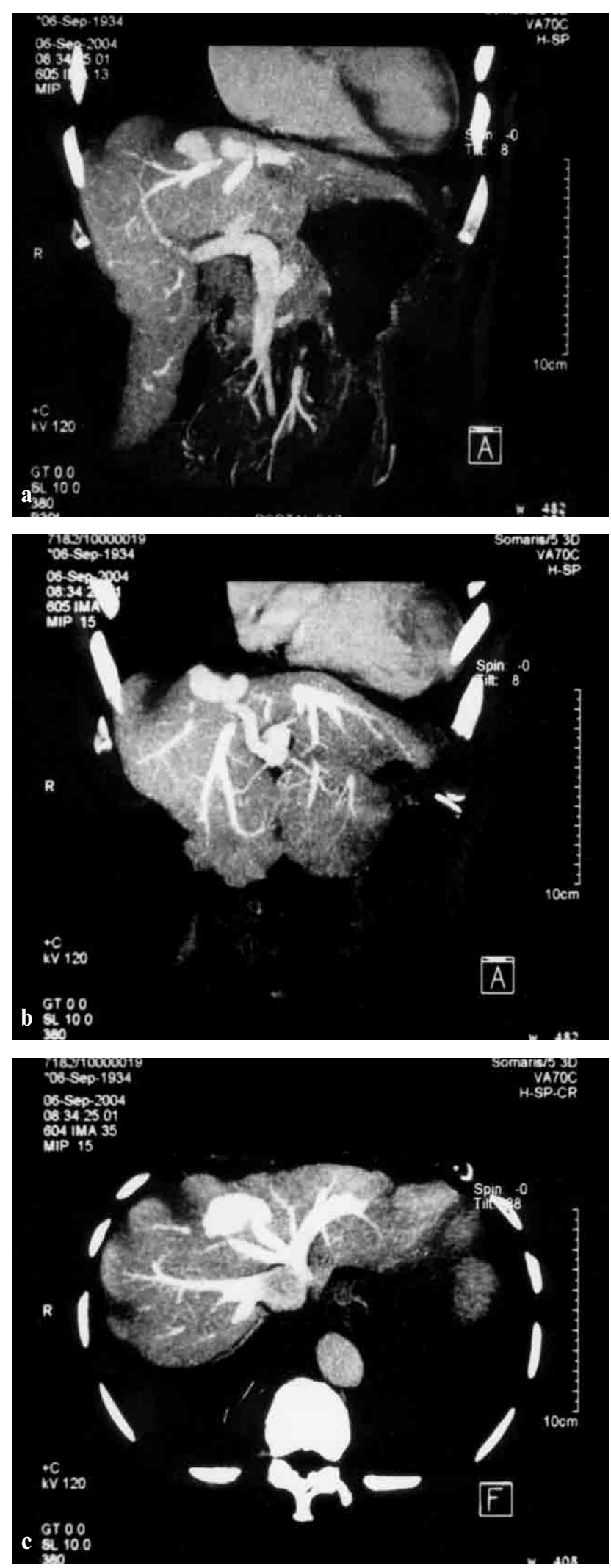

Fig. 1: CT-angiography appearances of portosystemic shunt in the patient. are found between peripheral branches of portal vein and hepatic veins in one hepatic segment. The third type is aneurysmal with peripheral portal and hepatic veins being connected through an aneurysm. The fourth type has multiple communications between peripheral portal and hepatic veins diffusely in both lobes. According to this classification, our patient had an aneurysmatic type 3 connection between left hepatic vein and left portal vein. Chevallier et al. did another classifications as follows: Type I includes patent paraumbilical veins, located in the liver, and commonly encountered in portal hypertension. Types II, III include shunts, unique or multiple, between the portal branch and the hepatic vein, located either in two adjacent liver segments (type II) or in non-adjacent liver segments (type III). Type IV corresponds to any tubular communication developed between the right portal branch and the inferior vena cava. The exceptional patent ductus venosus or a patent umbilical vein should not be considered as IPSVS since their course is strictly extrahepatic (4).

The diagnosis of intrahepatic portosystemic venous shunts can be established by color Doppler, CT-angiography, MRI or conventional angiography $(8,10,25,27,28)$. Color Doppler imaging demonstrate a direct communication of color flow signals between the portal vein and hepatic vein, in addition to the characterizationof the Doppler spectrum at each sampling point from a continuous waveform signal (portal vein) to a turbulent signal (aneurysmal cavity), and finally, to a biphasic waveform signal (hepatic vein). Color Doppler imaging is useful in the diagnosis of an intrahepatic portosystemic hepatic venous shunt, and the measurement of shunt ratio may be useful in the followup and determiming the therapeutic option (19). Magnetic resonance imaging also can clearly demonstrate the portalhepatic venous shunt due to "flow void". Multiple diffuse shunts or a solitary shunt can be visualized. The solitary shunt can be either tubular, focally dilated or racemose in configuration $(2,14,25,28)$. Color Doppler imaging and CT angiography are relatively non-invasive in diagnosis of SIPSVS.

The vascular malformation we present is believed to be a congenital anomaly, as no signs of cirrhosis or trauma were found. But, there are still many arguments about it. Even though certain embriyological events remain obscure, certain developmental aberrations may cause this vascular connection. Some authors postulates a persistent venous anastomosis such as ductus venosus and right vitelline vein. Others advocate an acquired cause from rupture of a portal venous aneurysm into the hepatic vein or from a dilated heptic vein communicating with the inferior vena cava via inferior phrenic and suprarenal vein $(5,10,14,19,21,28,29)$. Persistent ductus venosus could be a remote possibility in our case. Rupture of the portal vein aneurysm is more probable mechanism. Another case was reported of a newborn with a shunt with spontaneous resolve in first year of age $(8,13)$. SIPSVS may be demonstrated in any age of life between 20day-old and late seventies $(3,5,12,14,18,19,20,22,24,26,31)$. 
Wide range distribution in case reports may make us speculate role of different mechanism in development of SIPSVS.

Awareness of intrahepatic communications is important because they can cause encephalopathy, and most of these shunts have been reported to be completely cured by transcatheter embolization. Potential complications of coil embolization may include evolution of portal hypertension caused by abrupt changes in portal hemodynamics and dislodgement of coils into the systemic circulation. Retrograde transcaval obliterationis the least invasive technique and is recommended as the first choice for treatment of portosystemic venous shunt except in patients with multiple shunts. Surgical intervention such as shunt ligation anf hepatic resection, creation of an alternative portsystemic shunt are additional therapeutic approach descibed in literature (6, $17,21,26,31)$.

Intrahepatic shunts may cause neurocognitive abnormality. A 23-year-old female patient with complaint of fatigue was reported to have right portal vein aneurysmal communication in otherwise healthy woman. Neuropsychological testing, imaging, and MR spectroscopy revealed changes similar to that descirbed in patients with liver cirrhosis and subclinical hepatic encephalopathy. T1-weighted MRI showed a hyperintense globus pallidus, a feature seen in subjects with an without portal-encephalopathy. Portal systemic shunting in the absence of parenchymal liver disease reproduces neurological features descibed in cirrhosis (6). Because, she did not accept, we have not perform cerebral investigations in our patient.

This vascular abnormality accounts for the blood glucose problems: the portocaval shunt explains the early hyperglycemia by defective liver uptake of glucose and secondary hyperinsulinism occurs because of the reduced hepatic degradation of the insulin secreted in normal quantity. The late hyperinsulinism then leads to secondary hypoglycemia. These cases may benefit dietetic treatment $(7,9,12,18)$.

The size of SIPSVS has been reported to probably increase in time. However, in a year we have not seen a size change in the lesion of our patient. But, this issue remains to be defined with prospective studies.

In the literature, there are several reports of distinctive association with SIPSVS such as congenital biliary atresia, polycystic ovary syndrome, huge pelvic myoma, coronary artery fistulas, leptospirosis, hemangiomas and membranoproliferative glomerulonephritis. There are cases of SIPSVS associated with focal nodular hyperplasia or hereditary hemorrhagic telengiectasia (HHT) $(1,15,16,30,32)$. HHT is an autosomal dominant disorder characterized by telangiectasias and arteriovenous malformations of potentially every organ (3). Hepatic involvement occurs in $8-31 \%$ of cases. Hepatic involvement is shown by examination of biopsy, sonography, Doppler sonography, CT, and MR imaging. This pictorial essay illustrates the broad spectrum of abnormalities of hepatic vessels and collaterals in HHT that are detectable by imaging techniques even in the early or clinically silent stages of the diseases. The association between the hepatic vascular lesions and HHT is varied, ranging from telangiectasias to large shunts between three vascular channels. In an advanced stage of involvement, large portovenous shunts may be present. In another case, development of pulmonary hypertension was accepted to be due to SIPSVS. Because, it was assumed that vasoconstrictive agents whicih should be metabolized by the liver in normal subjects, passing through the intrahepatic shunt into the lung (11). Our patient had no abnormality that have been demonstrated. She had no complaint. Our patient underwent no treatment for the portosystemic shunt because she did not present with hepatic encephalopathy. That's why she was undertaken follow-up. One year later, there was nothing changed. Then we planned to follow her with intervals of two years.

In conclusion, clinicians sholud not be confused in incidental diagnosis of SIPSVS. However, when intrahepatic portosystemic shunt does present with hepatic encephalopathy, the correct diagnosis is required prior to appropriate treatment.

\section{References}

1. Aiba N, Morioka J, Myazono T, Okita H, Yata Y, Okada K, Nambu S, Izumi R. Case Report: intrahepatic portal-hepatic venous shunts associated with a large pelvic leiomyoma. J Gastroenterol Hepatol 1998;13(2): 158-62.

2. Araki T, Ohtomo K, Kachi K, Monzawa S, Hihara T, Ohba H, Ainoda T, Kumagai $\mathrm{H}$. Magnetic resonance imaging of macroscopic intrahepatic portosystemic venous shunts. Gastrointest Radiol 1991;16(3):221-4.

3. Buscarini E, Buscarini L, Civardi G, Arruzzoli S, Bossalini G, Piantanida M. Hepatic vascular malformations in hereditary hemorrhagic telangiectasia: imaging findings. AJR Am J Roentgenol 1994;163(5):1105-10.

4. Chevallier P, Oddo F, Souci J, Diaine B, Padovani B. Macroscopic intrahepatic portosystemic venous shunt. Pediat Radiol 1991;21(7):529-30

5. Cosme-Jimenez A, Bujanda Fernandez de Pierola L, Poch Zapirain M, Orcolaga Alba R, Ojeda Perez E, Arenas Mirave JI. Congenital intrahepatic venous shunt as a cause of hepatic encephalopathy. Gastroenterol Hepatol 1995;18(9):460-3.

6. Crespin J, Nemcek A, Rehkemper G, Blei AT. Intrahepatic portal-hepatic venous anastomosis: a portal-systemic shunt with neurological repercussions. Am J Gastroenterol 2000;95(6):1568-71.

7. Duprey J, Gouin B, Benazet MF, Le Gal J. Glucose intolerance and post stimulatory hypoglycemia secondary to a probably congenital intrahepatic portocaval anastomosis. Ann Med Interne 1985;136(8):655-8.

8. Gitzelmann R, Forster I, Willi UV. Hypergalactosemia in a newborn: self limiting intrahepatic portosystemic venous shunt. Eur J Pediatr 1997;156(9):719-22.

9. Gouin B, Le Gal J, Duprey J, Sanson J. Congenital intrahepatic portocaval anastomosis: analysis of manifested glucose abnormalities. Gasteroenterol Clin Biol $1984 ; 8(5): 464-8$

10. Grattagliano A, Rapaccini GL, Camaldo G, Pompili M, Marino P, Mastromatteo AM, Cotroneo AR, Gasbarrini G. Spontaneous intrahepatic portosystemic venous shunt in a patient with cirrhosis: diagnosis by combined color Doppler and pulse Doppler ultrasonography. Liver 1997;17(6): 307-10.

11. Hondo T, Teragawa H, Munemori M, Morishima N, Watanabe H, Ogata S, Ohe H, Yoshikawa M, Ohbayashi M. Portal hepatic venous shunt through a portal aneurysm complicated by hepatic encephalopathy and pulmonary hypertension. Intern Med 1997;36(11):790-3

12. Horiguchi Y, Kitano T, Imai H, Ohsuki M, Yamauchi M, Itoh M. Intrahepatic portal-systemic shunt: its etiology and diagnosis. Gastroenterol Jpn. 1987; 22(4):496-502.

13. Jabra AA, Taylor GA. Ultrasound diagnosis of congenital intrahepatic portosystemic venous shunt. Eur J Pediatr 1997;21(7):529-30.

14. Kakitsubata Y, Kakitsubata S, Kiyomizu H, Ogawa T, Kato T, Watanabe K. Intrahepatic portal-hepatic venous shunts demostrated by US, CT, and MRI imaging. Acta Radiol 1996;37(5):680-4.

15. Kantarci F, Mihmanli I, Kara B, Cantasdemir M, Adaletli I. Spontaneous intrahepatic portosystemic venous shunt in leptospirosis: is it rare association or coincidence? Eur Radiol 2003;13 Suppl 4:L235-6.

16. Karashima S, Hattori S, Nakazato H, Awata H, Seguchi S, Ikeda S, Sera Y, Endo F. Membranoproliferative glomerulonephritis in congenital portosystemic shunt without liver cirrhosis. Clin Nephrol 2000;53(3):206-11. 
17. Kim IO, Cheon JE, Kim WS, Chung JW, Yeon KM, Yoo SJ, Seo JK, Choi JH Congenital intrahepatic portosystemic venous shunt: treatment with coil embolization. Pediatr Radiol 2000;30(5):336-8.

18. Kozuka S, Sassa R, Kakumu S. An enormus intrahepatic shunt bwteen porta vein and hepatic one. Angiology 1975;26(4):365-71.

19. Kudo M, Tomita S, Tochio H, Minowa K, Todo A. Intrahepatic portosytemic venous shunt: diagnosis by color Dopple imaging. Am J Gastroenterol 1993; 88(5):723-9.

20. Kudo M. Intrahepatic portosystemic venous shunt in liver cirrhosis: is it congenital or acquired? AJR Am J Roentgenol 1993;160(2):421-2.

21. Maeda T, Mori H, Aikawa H, Komatsu E, Kagawa K. Therapeutic embolization of intrahepatic portosytemic shunts by retrograde transcaval cathetherization. Cardiovasc Intervent Radiol 1993;16(4):245-7.

22. Materne R, Van Beers BE. Images in clinical radiology. Spontaeous intrahepatic portosystemic venous shunt and focal nodular hyperplasia. J Belge Radio 1998;81(4): 180 .

23. Matsumoto R, Izutsu M, Kobayashi S, Kusano S. A case of multiple intrahepatic portosytemic venous shunts associated with multiple hemangioma-like lesions of the liver. Rinsho Hoshasen. 1990;35(9):1085-8.

24. Mori K, Dohi T, Yamamato H, Kamada M. An enourmous shunt between the portal and hepatic veins associated wit multiple coronary artery fistulas. Pediatr Radiol. 1990;21(1):66-8
25. Oguz B, Akata D, Balkanci F, Akhan O. Intrahepatic portosystemic venous shunt: diagnosis by color/power Doppler imaging and three dimensional ultrasound. Br. J Radiol. 2003;76(907):487-90

26. Paley MR, Farrant P, Kane P, Heaton ND, Howard ER, Karani JB. Developmental intrahepatic shunts of childhood: radiological features of management Eur Radiol 1997;7(9):1377-82.

27. Park JH, Cha SH, Han JK, Han MC. Intrahepatic portosystemic venous shunt. Am J Roentgenol. 1990;155(3):527-8.

28. Santamaria G, Pruna X, Serres X, Inaraja L, Zuasnabar A, Castellote A Congenital intrahepatic portosystemic venous shunt: sonographic and magnetic resonance imaging. Eur Radiol. 1996;6(1):76-8.

29. Satoh M, Yokoya S, Hachiya Y, Hachiya M, Fujisawa T, Hoshino K, Saji T. Two hyperandrogenic adolescent girls with congenital portosystemic shunt. Eur J Pediatr 2001;160(5):307-11.

30. Serrien B, Rigauts H, Marchal G, Lambrechts P. Congenital intrahepatic portosystemic shunt. J Belge Radiol 1992;75(6):492-4.

31. Tanoue S, Kyosue H, Komatsu E, Hori Y. Symptomatic intrahepatic portosystemic venous shunt: embolization with an alternative approach. AJR Am J Roentgenol 2003;181(1):71-8.

32. Yamagami T, Nakamura T, Tokiwa $\mathrm{K}$, Ohno K, Itoh H, Maeda T. Intrahepatic portosystemic venous shunt associated with biliary atresia: case reprt. Pediatr Radiol. 2000;30(7):489-91.

Submitted May 2006.

Accepted November 2006

\section{Corresponding author:}

Levent Filik, M.D., Kucukesat Cad. Bankaci sok. Osman Gurbuz Apt. 21-10 Kavaklidere, Ankara, 06600 Turkey, e-mail: leventfilik@yahoo.co.uk 